\title{
Evidence of sibling species between two host-associated populations of brown planthopper, N. lugens (stål) (Homoptera: Delphacidea) complex based on morphology and host-plant relationship studies
}

\begin{abstract}
Morphological and hostï plant relationship studies were conducted to differentiate two sympatric populations of brown planthopper (BPH), Nilaparvata lugens, one from rice (Oryza sativa) and the other from Leersia hexandra, a weed grass. In morphometric studies based on esterase activities, an UPGMA dendrogram using 17 quantitative morphological characters, including stridulatory organs (courtship signal-producing organs) between two sympatric populations of N. lugens, one from rice and the other from L. hexandra, a weed grass revealed that both populations were separated from each other. An out-group, N. bakeri, was found to be completely different from the two sympatric populations of $\mathrm{N}$. lugens. Rice plants were best suited for the establishment of the rice-infesting population, and L. hexandra was a favourable host for the Leersia-infesting population. The individuals derived from one host did not thrive on the other host, as shown by a significant reduction in survival and nymphal development, ovipositional preferences, ovipositional response, and egg hatchability. Therefore, morphological and hostï plant relationship studies indicate that rice-associated population with high esterase activities and L. heaxandra-associated population with low esterase activities are two closely related sibling species.
\end{abstract}

Keyword: Morphology; Hostï plant relation; Brown plant hopper complex; Biological species 